\title{
Dietary sodium intake induced myenteric neuron hypertrophy in Wistar rats
}

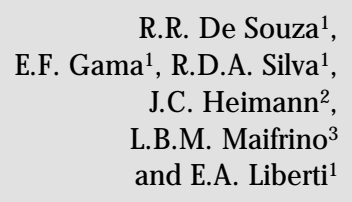

R.R. De Souzaㄹ,

E.F. Gama1, R.D.A. Silva1,

J.C. Heimann²,

L.B.M. Maifrino 3

and E.A. Liberti ${ }^{1}$

${ }^{1}$ Departamento de Anatomia, Instituto de Ciências Biomédicas, and

${ }^{2}$ Laboratório de Fisiologia Renal, Departamento de Nefrologia,

Faculdade de Medicina, U niversidade de São Paulo, São Paulo, SP, Brasil

Instituto Dante Pazzaneze de Cardiologia, São Paulo, SP, Brasil

\section{Correspondence \\ R.R. De Souza \\ Departamento de Anatomia, ICB, USP \\ Av. Prof. Lineu Prestes, 2415 \\ 05508-900 São Paulo, SP \\ Brasil \\ Fax: +55-11-818-7366 \\ E-mail: rrdsouza@ icb.usp.br}

Publication supported by FAPESP.

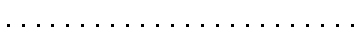

Received July 12, 1999

Accepted March 22, 2000

\section{Abstract}

In the present study we investigated the effect of salt intake on myenteric neuron size of the colon of adult male Wistar rats. The animals were placed on either a high-salt (HS; 8\%; 12 animals) or a low-salt diet (LS; $0.15 \%$; 12 animals) for 15 or 52 weeks and blood pressure was measured. The sizes of myenteric neurons of the distal colon from both groups were measured. No difference in neuron size was observed between the HS and LS groups after 15 weeks. After 52 weeks on HS, neuron size was increased $(\mathrm{P}<0.005)$ when compared with the LS group. The rats also presented hypertension, which was significantly different at 52 weeks ( $142 \pm 11$ vs $119 \pm 7 \mathrm{mmHg})$. These results suggest that a long time on an HS diet can significantly increase myenteric nerve cell size.

In recent years it has become apparent that a high-sodium diet has a clear doserelated trophic effect on some types of cells. An increased dietary sodium intake may induce growth of vascular smooth muscle cells (1) and cardiac muscle cells $(2,3)$. In addition, previous studies from our laboratory have shown that sodium intake has a significant effect on neuron size. It has been demonstrated that an increase in dietary sodium for 48 weeks induced an increase in cardiac neuronal size (4). However, no information is available about the effects of dietary sodium on other types of nerve cells. Neurons in the wall of the intestine (myenteric neurons) contribute to its innervation and have a significant influence on intestinal function (5).
The objective of the present study was to determine if increased dietary sodium intake with normal regulation of volume balance causes modifications in the myenteric neurons of the colon. Wistar rats were exposed to a high dietary sodium intake for 15 and 52 weeks and myenteric neuron size was measured.

Rats at 3 weeks of age $(\mathrm{N}=24)$ were housed two per cage on a 12-h light/dark cycle and were given tap water ad libitum. Diets with the following sodium concentrations were used: $8 \% \mathrm{NaCl}$-containing food as the high-sodium diet $(\mathrm{N}=12)$ and $0.15 \%$ $\mathrm{NaCl}$-containing food as the low-sodium diet (control animals, $\mathrm{N}=12$ ). The animals were killed with ether: 12 animals (6 rats on the high-sodium diet and 6 rats on the low-so- 
dium diet) after 15 weeks and 12 animals (6 rats on the high-sodium diet and 6 rats on the low-sodium diet) after 52 weeks. The abdomen was opened and the 5-cm distal end of the sigmoid colon removed. The neurons of the myenteric ganglia were stained by a histochemical technique to detect DPNH-tetrazolium reductase activity (6). The pieces were then immersed in the incubation medium at room temperature and the reaction was stopped by immersing them in buffered neutral $10 \%$ formalin when the stain was sufficiently intense $(50 \mathrm{~min})$. The colon of each animal was opened, the mucosa and submucosa were removed and the tunica muscularis externa was mounted in glycerin jelly for microscopic examination. The profiles of 20 randomly chosen nerve cell perikarya were determined for each $1-\mathrm{cm}$ segment of the colon. This procedure was performed to avoid estimations of nerve cell perikarya in a region of the colon where the neurons are more concentrated. Thus, 100 nerve cell perikarya per animal were outlined on drawing paper using a camera lucida attached to the microscope. The areas of these cell bodies were estimated using a digitizing pad.

The ranges of myenteric neuron soma size groups (control and high-sodium diet rats) were plotted on frequency histograms which were compared by the chi-square test.

The myenteric plexus studied by the NADH-diaphorase method showed several ganglia containing variable numbers of neurons readily recognizable in the distal colon of all groups of rats (Figure 1).

The ranges of neuron soma size in rats placed on a high-sodium diet for 15 and 52 weeks are shown in Figure 2. No significant difference in neuron size was observed between the high-salt and low-salt groups after 15 weeks of diet (Figure 2A). Figure 2B shows the changes in neuron size occurring in rats receiving a high-salt diet for 52 weeks. These animals exhibited a significant increase in the number of large neurons (larger than $\left.500 \mu \mathrm{m}^{2}\right)(\mathrm{P}<0.05)$. There was also an elevation in tail arterial blood pressure in rats on a high-salt diet. At 15 weeks it was $134 \pm 16 v s 128 \pm 9 \mathrm{mmHg}$ and at 52 weeks, $142 \pm 11$ vs $119 \pm 7 \mathrm{mmHg}$, which was significantly different.
Figure 1 - DPNH-tetrazolium reductase-stained myenteric ganglia of rats on low- and high-sodium diets. Rats received 0.15 (A) or $8 \% \mathrm{NaCl}$ in their diets for 15 weeks (B) or 52 weeks (C). Nerve cell bodies (arrows) are intensely stained, except for the nucleus. Magnification bars: A-C $=20 \mu \mathrm{m}$.

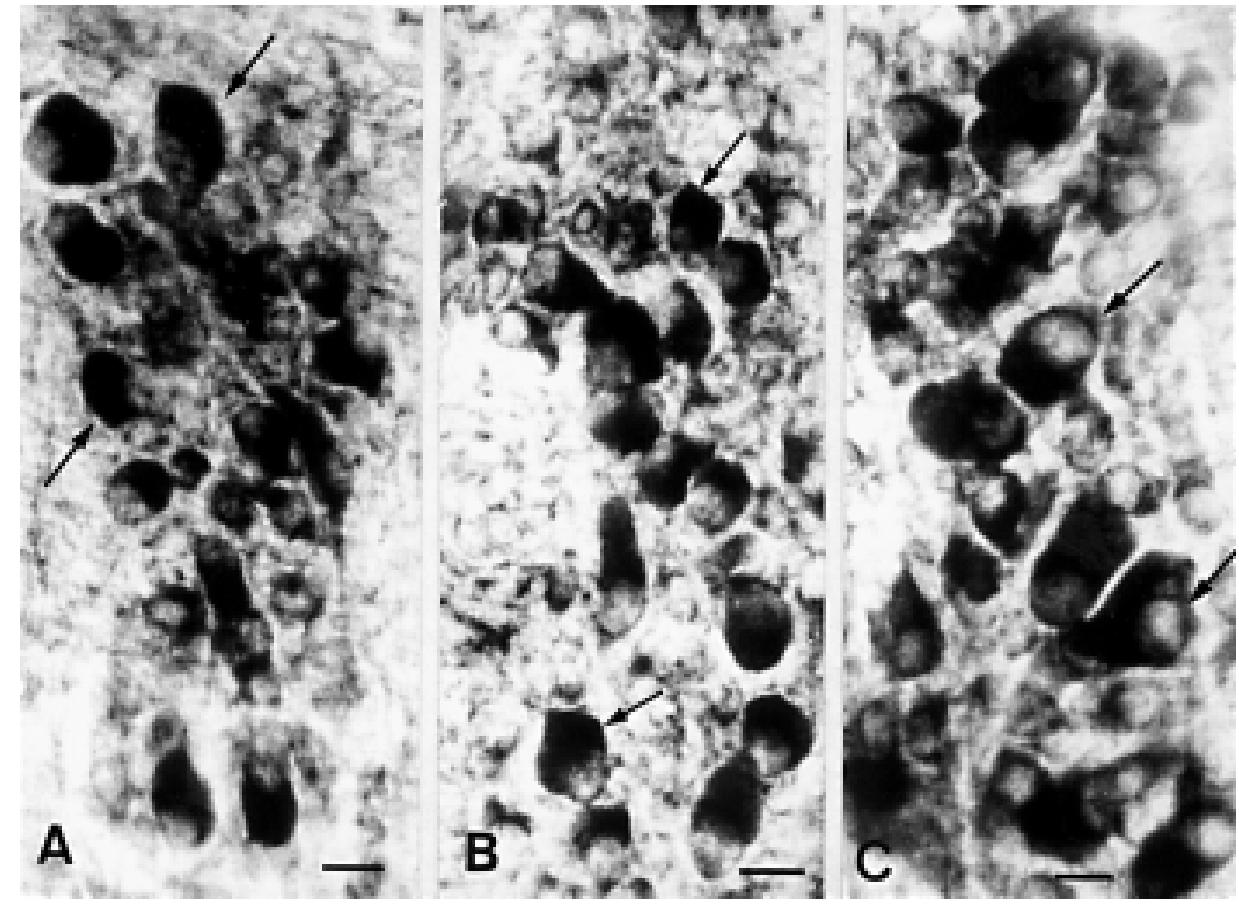


The present study is the first to examine the changes in myenteric neurons in response to dietary salt intake. Neuron soma sizes were increased in rats maintained on a highsalt diet for 52 weeks compared to rats placed on a low-salt diet. They were larger than those present in the rectum of normal adult rats whose area ranged from 175 to $275 \mu \mathrm{m}^{2}$ (7). Also, they were larger than the colonic neurons of Calomys callosus which showed a mean profile area of $206 \pm 5 \mu \mathrm{m}^{2}$ (8). However, in rats maintained on a high-salt diet for 15 weeks, no difference in neuron size was found between the low- and highsalt groups. These data suggest that a long time on a high-salt diet was in part responsible for the neuronal hypertrophy induced by a high-salt diet. This study showed that an increase in myenteric neuronal size takes place in the saline-treated rats. The observations of Gama et al. (4) on the cardiac neurons are confirmed by the present data on the colonic myenteric neurons. It is clear that a considerable potential for growth is maintained by the neurons of the colon of mature animals. The process of hypertrophy occurs in both the cardiac and the myenteric neurons: the two sets of neurons respond to the high-sodium diet in a similar way, even if one plexus is truly intramuscular (the myenteric plexus) and the other (the cardiac plexus) is embedded in the connective tissue of the atria.

The mechanism whereby a high-salt intake can influence cell size remains obscure. It was proposed that increased dietary sodium intake may induce growth of vascular smooth muscle cells via release of a growth factor (1). Thus, it is possible that this effect

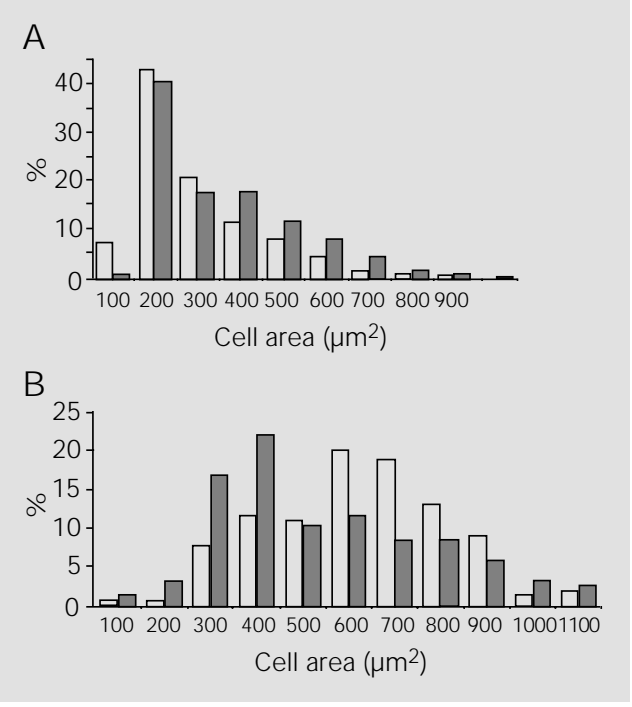

can also enhance the growth of myenteric nerve cells. Another possibility is that an increased sodium influx could stimulate intracellular protein synthesis. The enhanced protein synthesis as a result of increased sodium influx could be explained by an enhanced $\mathrm{Na}^{+} / \mathrm{H}^{+}$exchange, which will alkalinize the cell. This high $\mathrm{pH}$ has been found to precede cell growth in a variety of cells (9). This hypothesis is strengthened by the observation that the $\mathrm{Na}^{+} / \mathrm{H}^{+}$exchange blocker, amiloride, inhibits the increased protein synthesis (2). High dietary sodium might increase sodium levels in the interstitium of the ganglia, which could result in an increased sodium influx via the $\mathrm{Na}^{+} / \mathrm{H}^{+}$exchange and an enhanced protein synthesis. It seems that only a prolonged increase in intracellular sodium will sufficiently enhance the $\mathrm{Na}^{+} / \mathrm{H}^{+}$exchange to stimulate protein synthesis. However, further studies should be performed to confirm this hypothesis.
Figure 2 - Effect of high-salt dietary intake on myenteric neuron cell size. Rats received 0.15 (filled bars - low-sodium diet) or $8 \%$ (open bars - high-sodium diet) $\mathrm{NaCl}$ in their diets for 15 weeks (A) or 52 weeks (B). Data are reported as histograms of neuronal cell profile area for 600 neurons measured in colon tissue from 6 rats in each group (chi-square test).

\section{References}

1. Aviv A (1990). Salt sensitivity: trophic effect of growth and vasoactive factors. Hypertension, 16: 103.

2. Kent RL, Hoober KJ \& Cooper G (1989). Load responsiveness of protein synthesis in adult myocardium: role of cardiac defor- mation linked to sodium influx. Circulation Research, 64: 74-85.

3. Harmsen E \& Leenen FHH (1992). Dietary sodium induced cardiac hypertrophy. Canadian J ournal of Physiology and Pharmacology, 70: 580-586.
4. Gama EF, Ferraz-de-Carvalho CA, Vasconcelos DC, Lima NKC, Heimann J C \& DeSouza RR (1996). Dietary sodium intake and cardiac nerve cell hypertrophy in Wistar rats. Brazilian J ournal of Medical and Biological Research, 29: 363-365. 
5. Furness J B \& Costa M (1987). The Enteric Nervous System. Churchill Livingstone, New York.

6. Gabella G (1987). The number of neurons in the small intestine of mice, guinea-pig and sheep. Neuroscience, 22: 737-752.

7. Gabella G (1971). Neuron size and num- ber in the myenteric plexus of the newborn and adult rat. J ournal of Anatomy, 109: 81-95.

8. Maifrino LBM, Prates J C, De-Souza RR \& Liberti EA (1997). Morphometry and acetylcholinesterase activity of the myenteric plexus of the wild mouse Calomys callo- sus. Brazilian J ournal of Medical and Biological Research, 30: 627-632.

9. Soltoff SP \& Cantley LC (1988). Mitogens and ion fluxes. Annual Review of Physiology, 50: 207-223. 